\title{
Vasculogenic Mimicry in Merkel Cell Carcinoma
}

van Beurden $\mathrm{A}^{1^{*}}$, van Dijk $\mathrm{CM}^{2}$ and Baeten $\mathrm{CIM}^{3}$

${ }^{1}$ Department of surgery, Groene Hart Ziekenhuis, Gouda, The Netherlands

${ }^{2}$ Department of pathology, Groene Hart Ziekenhuis, Gouda, The Netherlands

${ }^{3}$ Department of surgery, Leids Universitair Medisch Centrum, Leiden, The Netherlands

"Corresponding author: Anne van Beurden, Kastanjelaan 13, 3737 RA Groenekan, The Netherlands, Tel: +31611231594; E-mail: annevanbeurden@hotmail.com Rec date: Feb 20, 2014, Acc date: Apr 23, 2014, Pub date: Apr 25, 2014

Copyright: (c) 2014 Beurden AV, et al. This is an open-access article distributed under the terms of the Creative Commons Attribution License, which permits unrestricted use, distribution, and reproduction in any medium, provided the original author and source are credited.

\section{Abstract}

Aims: Angiogenesis, as measured by degree of micro vessel density, has been associated with tumor progression in many tumor types, but does not always correlate with clinical outcome. Aggressive tumor cells were shown to form blood-conducting tubes not lined by endothelial cells, and this phenomenon was termed vasculogenic mimicry. Merkel cell carcinoma is a very aggressive but rare form of skin cancer, of neuroendocrine origin and with increasing incidence. We investigated the presence of vasculogenic mimicry in Merkel cell carcinoma in the Groene Hart Hospital, The Netherlands between 1990-2012.

Methods: Tumor tissues of all patients diagnosed with primary Merkel cell carcinoma in the period 1990-2012 in the Groene Hart Ziekenhuis were assessed on the presence of vasculogenic mimicry.

Results: We found vasculogenic mimicry in $11(100 \%)$ out of the eleven patients primary diagnosed with Merkel cell carcinoma.

Conclusions: Vasculogenic mimicry is present in all Merkel cell carcinoma we found in our database and appears to be comparable to vasculogenic mimicry described in other tumors. Further investigation to vasculogenic mimicry can probably help us in finding a better understanding of the behaviour of Merkel cell carcinoma consequently a better treatment.

Keywords: Vasculogenic mimicry; Merkel cell carcinoma; PAS loops; Bloodlakes; Vasculature

\section{Introduction}

Nowadays there is enough evidence that tumors acquire microcirculation not only by angiogenesis. The concept of Vasculogenic Mimicry (VM) by melanoma cells was introduced in 1999 by Maniotis and is the ability of aggressive melanoma cells to form Extracellular Matrix (ECM)-rich vasculogenic-like networks. One form of $\mathrm{VM}$ is a histological pattern in tumors detected by Periodic Acid Schiff (PAS)-staining (PAS loops). Another form of VM refers to cancer cells directly lining tumor spaces or channels, which contain erythrocytes (blood lakes). Both forms are a result of dedifferentiation by aggressive melanoma cells adapting an embryonic-like phenotype [1]. Since the first description of Vasculogenic Mimicry (VM) this concept is found in other aggressive tumor [2].

Merkel cell carcinoma is a rare primary cutaneous neuroendocrine carcinoma that has been first described by Toker in 1972 [3]. This rare aggressive neoplasm is thought to originate from Merkel cells which are located in the basal layer of the epidermis and contain neurosecretory granules [4-6]. It usually presents itself as a nonmeaningful lesion and the diagnosis is rarely suspected at the time of biopsy. Because of increasing incidence and the discovery of a possible polyoma virus association, interest in Merkel Cell Carcinoma (MCC) has escalated [7]. Data from the US Surveillence, Epidemiology, and
End Results (SEER) Program show an incidence of Merkel cell carcinomas of 0.23 per 100000 people in white populations. The incidence in black populations is about a twentieth of this number. Most cases occur in elderly people, with the average age of presentation being 69 years; only 5\% of the cases occur before the age of 50 years [8]. RW Miller and CS Rabkin, Merkel cell carcinoma and melanoma: etiological similarities and differences, Cancer Epidemiol Biomarkers Prev8 (1999), pp. 153-158. View Record in Scopus | Cited By in Scopus (157) Comprehensive reviews suggest that the incidence of MCC is slightly higher in men. They occur most commonly in areas of the body that are exposed to the sun, with $50 \%$ occurring in the head and neck region (especially peri-orbital) and about $40 \%$ occurring in the extremities [8]. MCC is particularly aggressive with a reported 5-year survival of $30 \%$ to $74 \%$ [9-11]. MCC seems to depend greatly on stage, with stage I disease having survival rates as high as $81 \%$ [9].

Many patients present with already metastasis at first presentation, and there is a high risk of local, regional, and distant recurrence despite treatment. Review of literature reveals that the overall local recurrence rate is about $25 \%$, and regional lymph node involvement occurs in up to $52 \%$ of the cases. Moreover distant metastases occur in $34 \%$ of the patients, with a similar percentage survival of the disease [12].

Various clinical and histologic variables have been cited as indicators of a poor prognosis, including male sex, patient age, tumor location [10-13], large tumor, small cell size, and high mitotic rate 
[14]. However, the most important prognostic factor is the stage of the disease [9].

The high survival rate for stage I lesions indicates the importance of early recognition and treatment of these tumors. As in other tumors, where VM has been associated with aggressiveness, we performed this study to detect VM in MCC. Still little is known about the pathophysiology of MCC and metastasis. It is possible that VM detection in MCC can help us to understand the pathophysiology and might help us finding a better prediction of prognosis and as a result a better treatment.

\section{Material and Methods}

This retrospective study included all patients with MCC diagnosed in the Groene Hart Hospital between 1990-2012, as registered in the database of the department of pathology in the Groene Hart Hospital, Gouda, The Netherlands. Clinical data, such as location of carcinoma, date of diagnosis, metastasis and death were extracted from personal health records. Additional data were acquired by contacting the general practitioner or other hospitals if patients were referred. All data were collected and analysed anonymously and the maximum follow-up was 24 years.

All tissues were cutaneous MCC, proven by positive immunohistochemical staining with cytokeratin 20, CD 56, chromogranin $\mathrm{A}$ and synaptophysin and by negative immunoreactivity with cytokeratin 7 and TTF-1 (all Dako Denmark). The slides were coded anonymous to the examiners. The examiners did not have any clinical information. The presence of PAS loops was scored as present or absent. Each tumor was scored for the presence of PAS loops (parallel cross linked patterns or back to back loops (Magnification 40x-100x Leica microscope) [15]. Blood lakes were scored as present or absent, tumor cells directly lining erythrocytes observed with magnifications between 100x-400x [16].

\section{Results}

Eleven consecutive patients were diagnosed with primary MCC in the Groene Hart Hospital between 1990 and 2012. No patients were excluded of 11 patients, 8 were female (73\%). Mean age was 76 years at time of diagnosis (range 52-91 years). The median survival was 43 months (range 2-123 months). Four tumors were located on the cheek, 1 on the eyelid, 1 on the ear, 1 on the nose, 1 on the scalp, 1 on the leg, 1 on the arm and of 1 tumor the primary location was unknown. Four patients $(36 \%)$ developed proven metastasis during follow-up and one patient (9\%) developed a local recurrent tumor (Table 1). During follow-up 5 patients (45\%) died. Two of them died as a result of MCC. One patient died postoperatively after resection of the MCC as a result of respiratory distress based on a exacerbation of COPD. Of two patients the cause of death is unknown. One of these patients had a MCC on the cheek with metastasis in the glandulaparotis and another patient had a MCC on the nose of which the excision was not radical but because of his age no re-excision was performed. It is plausible that also in these two patients the MCC was the primary cause of death.

\section{Vasculogenic Mimicry (VM)}

Out of 11 tumors, VM (blood lakes as well as PAS loops) was detected in $11(100 \%)$ (Figure 1$)$. We detected VM especially in the more central parts of the tumor areas. These parts were not at the border of the resection and are not likely to be associated with mechanical damage due the fact that none of the immunehistochemical stained sections showed blood clotting. The parts that showed PAS loops are not always the same parts in which blood lake formation was found.

\begin{tabular}{|l|l|l|l|l|}
\hline & $\mathbf{N}$ & $\begin{array}{l}\text { Survival } \\
\text { (months) }\end{array}$ & $\begin{array}{l}\text { Hematogeneous } \\
\text { metastasis }\end{array}$ & $\begin{array}{l}\text { Lymfogeneous } \\
\text { metastasis }\end{array}$ \\
\hline Stage I & 4 & $41.5(7-86)$ & 0 & 0 \\
\hline Stage II & 3 & $13(2-29)$ & 0 & 0 \\
\hline Stage III & 3 & $61(24-123)$ & 1 & 3 \\
\hline Stage IV & 1 & 84 & 1 & 0 \\
\hline
\end{tabular}

Table 1: Patients survival rate at different stages of Metastasis
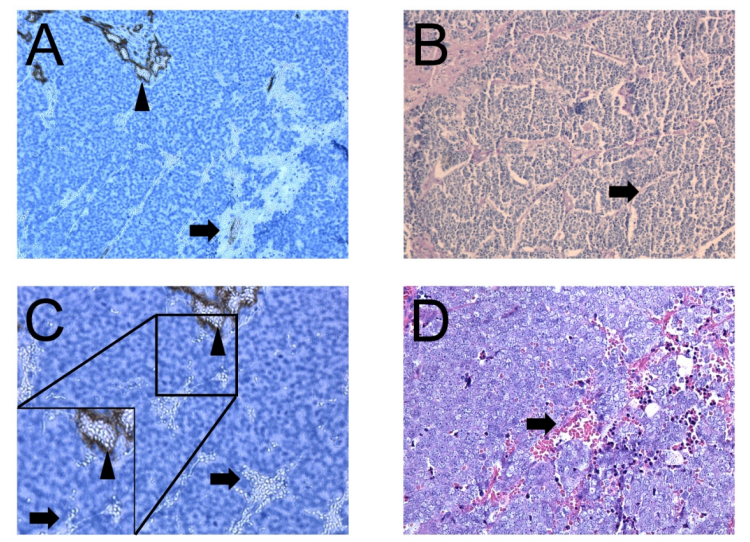

Figure 1: A) Vasculogenic mimicry in Merkel cell carcinoma (Stage 3) indicated by the presence of intratumoral extra vascular erythrocytes (next to regular endothelial cell-lined blood vessels). Hematoxylin and eosin-stained Merkel cell tumor sections stained with CD34. Regular blood vessels are sharp by arrowheads, and areas of vasculogenic mimicry are identified by arrows (Magnification 100x). B) Vasculogenic mimicry in Merkel cell carcinoma indicated by the presence of a histological pattern detected by periodic acid Schiff (PAS)-staining (PAS loops) (magnification 100x). C) CD34 counterstained with hematoxylin and eosin Merkel cell tumor (stage 1) sections (Magnification 200x). With a zoom of the normal blood vessels (arrowheads) and bloodlakes (arrows). D) Merkel cell carcinoma (Stage 2), hematoxylin and eosin stained (magnification 100x). Bloodlake identified by arrow. 


\section{Discussion}

In this study we showed that VM can occur in MCC. To our knowledge, VM has not been previously described in MCC. In our population $36 \%$ of the patients had proven metastasis of MCC which is in accordance with literature [12]. Two of our patients died as a result of MCC and of two patients the cause of death is unknown, but it is very well possible that these patients also died of MCC.

The survival measured in our population (mortality of $45 \%$ ) is in concordance to most MCC populations (mortality rates range from 20-55\%), though we were not able to differ between stages in this small study population [17]. One patient in stage 3 had a sentinel node excision with proven metastasis; in the radical axillary lymph node dissection no other metastasis were found. This patient also received radiotherapy in the area of primary location and axillary afterwards and this probably explains a survival of more than 10 years.

We think that the presence of VM in MCC is similarly associated with poor survival and metastasis as described in cutaneous melanoma [18]. Indeed, in Merkel cell carcinoma we founda PAS-loop pattern similar to the one described in melanoma (Figure 1). Next to PASloops, also blood-lakes were detected. We found both forms in all MCC, though not all areas in a section show these specific characteristics. It is more often to be found in the more central parts of a section. The PAS-loops may be a precursor form of blood lakes and therefore both forms can often be detected in each-others each-other's surrounding.

From literature is known that MCC is a very aggressive carcinoma, comparable with aggressive melanoma that is at time of diagnosis often metastasized. We know that in more common carcinomas as colon and breast the phenomenon of VM also occurs though very less common. That MCC shows VM in all cases suggests that these tumors can already metastasize in an early stage. This is in concordance withEwing sarcoma and pheochromocytoma [16,19]. Like MCC these are also cancers of neuroendocrine origin (and also show VM). Studies have suggested that MCC derives from a primitive stem cell which is capable to epithelial or neuro-endocrine differentiation [20,21]. In Ewing sarcomas as well as in MCCs the cell cycling marker, Ki-67, is usually highly positive. These strongly proliferative tumors exhibit a high level of angiogenic signalling [16,22]. A hypothesis is that the angiogenesis cannot keep up with the high angiogenic signalling, and as a result the tumor is driven to form an alternative route for its nutritional needs.

Nowadays there is more information about a possible primary trigger for MCC formation by the Polyomavirus [7]. It is unclear why the possible primary trigger by the Polyomavirus of MCC results in such an aggressive carcinoma. Moreover only little information is available on the genetic alterations in MCC. Cytogenetic studies have not shown recurrent chromosomal changes, although various structural chromosome 1 rearrangements appear to be frequent, including deletions (often leading to loss of distal 1p material) [23]. One of the more commonly observed rearrangements detected by cytogenetic or loss of heterozygosity methods is a distal deletion involving 1p35-36 [23]. This area on chromosome 1 is often affected in malignant melanoma, pheochromocytoma, and neuroblastoma. The cells constituting these 3 tumors are of neural crest origin, a derivation that has also been proposed for the Merkel cell $[23,24]$. This might implicate those Merkel cell carcinogenesis shares pathogenetic mechanisms with other neoplasms of neural crest derivation which need to be studied in the future.
Despite the high metastatic rate associated with Merkel cell carcinoma, spontaneous regression has been reported, and there have been some therapeutic successes. This is almost similar to the results known from melanoma. The high survival rate for stage I lesions indicate the importance of early recognition and treatment of these tumors [9]. In our study there were four patients with stage I MCC with a median survival of 41.5 months. This is relatively low compared to literature with reported 5-years survival rates as high as $81 \%$ [9]. The survival of stage II, III and IV was 13, 61 and 84 months respectively which is in contrast with literature. Our study population is too small to draw any conclusions regarding survival of MCC. Of two patients with stage I and II MCC with short survival (2 and 7 months) MCC has not been proven to be the cause of death. However, one had an irradical resection and might have died of MCC.

In conclusion this study shows that vasculogenicmimicry can occur in Merkel cell carcinoma and appears to be comparable to vasculogenicmimicry described in other tumors.

\section{References}

1. Maniotis AJ, Folberg R, Hess A, Seftor EA, Gardner LM, et al. (1999) Vascular channel formation by human melanoma cells in vivo and in vitro: vasculogenic mimicry. Am J Pathol 155: 739-752.

2. Hendrix MJ, Seftor EA, Hess AR, Seftor RE (2003) Vasculogenic mimicry and tumour-cell plasticity: lessons from melanoma. Nat Rev Cancer 3: 411-421.

3. Toker C (1972) Trabecular carcinoma of the skin. Arch Dermatol 105: 107-110.

4. McAfee WJ, Morris CG, Mendenhall CM, Werning JW, Mendenhall NP, et al. (2005) Merkel cell carcinoma: treatment and outcomes. Cancer 104: 1761-1764.

5. Payne MM, Rader AE, McCarthy DM, Rodgers WH (2004) Merkel cell carcinoma in a malignant pleural effusion: case report. Cytojournal 1: 5.

6. Youker SR, Billingsley EM (2005) Combined Merkel cell carcinoma and atypical fibroxanthoma. J Cutan Med Surg 9: 6-9.

7. Feng H, Shuda M, Chang Y, Moore PS (2008) Clonal integration of a polyomavirus in human Merkel cell carcinoma. Science 319: 1096-1100.

8. Poulsen M (2004) Merkel-cell carcinoma of the skin. Lancet Oncol 5: 593-599.

9. Allen PJ, Zhang ZF, Coit DG (1999) Surgical management of Merkel cell carcinoma. Ann Surg 229: 97-105.

10. Smith KJ, Skelton HG 3rd, Holland TT, Morgan AM, Lupton GP (1993) Neuroendocrine (Merkel cell) carcinoma with an intraepidermal component. Am J Dermatopathol 15: 528-533.

11. Yiengpruksawan A, Coit DG, Thaler HT, Urmacher C, Knapper WK (1991) Merkel cell carcinoma. Prognosis and management. Arch Surg 126: 1514-1519.

12. Akhtar S, Oza KK, Wright J (2000) Merkel cell carcinoma: report of 10 cases and review of the literature. J Am Acad Dermatol 43: 755-767.

13. Shaw JH, Rumball E (1991) Merkel cell tumour: clinical behaviour and treatment. Br J Surg 78: 138-142.

14. Skelton HG, Smith KJ, Hitchcock CL, McCarthy WF, Lupton GP, et al. (1997) Merkel cell carcinoma: analysis of clinical, histologic, and immunohistologic features of 132 cases with relation to survival. J Am Acad Dermatol 37: 734-739.

15. Warso MA, Maniotis AJ, Chen X, Majumdar D, Patel MK, et al. (2001) Prognostic significance of periodic acid-Schiff-positive patterns in primary cutaneous melanoma. Clin Cancer Res 7: 473-477.

16. van der Schaft DW, Hillen F, Pauwels P, Kirschmann DA, Castermans K, et al. (2005) Tumor cell plasticity in Ewing sarcoma, an alternative circulatory system stimulated by hypoxia. Cancer Res 65: 11520-11528. 
Citation: van Beurden A, van Dijk CM, Baeten CIM (2014) Vasculogenic Mimicry in Merkel Cell Carcinoma. J Cytol Histol 5: 241. doi: 10.4172/2157-7099.1000241

Page 4 of 4

17. Heath M, Jaimes N, Lemos B, Mostaghimi A, Wang LC, et al. (2008) Clinical characteristics of Merkel cell carcinoma at diagnosis in 195 patients: the AEIOU features. J Am Acad Dermatol 58: 375-381.

18. van Beurden A, Schmitz RF, van Dijk CM, Baeten CI (2012) Periodic acid Schiff loops and blood lakes associated with metastasis in cutaneous melanoma. Melanoma Res 22: 424-429.

19. Favier J, Plouin PF, Corvol P, Gasc JM (2002) Angiogenesis and vascular architecture in pheochromocytomas: distinctive traits in malignant tumors. Am J Pathol 161: 1235-1246.

20. Merot $Y$ (1990) Is the neuroendocrine carcinoma of the skin a Merke cell tumor? What we can learn from immunohistochemical and ultrastructural studies. Int J Dermatol 29: 102-104.
21. Kroll MH, Toker C (1982) Trabecular carcinoma of the skin: further clinicopathologic and morphologic study. Arch Pathol Lab Med 106: 404-408.

22. Carson HJ, Reddy V, Taxy JB (1998) Proliferation markers and prognosis in Merkel cell carcinoma. J Cutan Pathol 25: 16-19.

23. Van Gele M, Van Roy N, Ronan SG, Messiaen L, Vandesompele J, et al. (1998) Molecular analysis of 1p36 breakpoints in two Merkel cell carcinomas. Genes Chromosomes Cancer 23: 67-71.

24. Vortmeyer AO, Merino MJ, Böni R, Liotta LA, Cavazzana A, et al. (1998) Genetic changes associated with primary Merkel cell carcinoma. Am J Clin Pathol 109: 565-570. 